\title{
Towards collaboration as learning: evaluation of an open CPD opportunity for $\mathrm{HE}$ teachers
}

\author{
Chrissi Nerantzi* and Peter Gossman \\ Centre for Excellence in Learning and Teaching, Manchester Metropolitan University, \\ Manchester, UK
}

(Received 12 December 2014; final version received 22 July 2015)

\begin{abstract}
Flexible, Distance and Online Learning (FDOL) is an open online course offered as an informal cross-institutional collaboration based on a postgraduate module in the context of teacher education in higher education. The second iteration, FDOL132, was offered in 2013 using a problem-based learning (PBL) design (FISh) to foster collaborative learning. How this was experienced by participants and how it affected learning within facilitated small groups are explored in this paper. Findings show that authentic learning in groups can be applied directly to practice, and greater flexibility and a focus on the process of collaborative learning has the potential to increase engagement and learning.
\end{abstract}

Keywords: academic development; problem-based learning; open educational practice; phenomenography

\section{Introduction}

This paper reports on an evaluation of an aspect of a Flexible, Distance and Online Learning (FDOL) optional 30 credit module, part of a Postgraduate Certificate in Academic Practice at an English higher education (HE) institution. FDOL was developed to meet an institutionally identified need to develop online flexible provision and build teaching capacity in this area (Appendix 1 contains the module aims and the learning outcomes). FDOL was also run as an open and openly licensed course to explore how such an approach might promote engagement with staff development through distributed online cross-disciplinary and cross-cultural professional communities.

Weller (2014) talks about the pedagogy of openness 'which makes use of open content, such as open educational resources, videos and podcasts, but also places an emphasis on the network and the learner's connections within this' (p. 10). The course discussed in this article is in line with the above and can also be characterised as a 'little OER' project (Weller 2011, 2014). This 'little OER' was developed by the author (Chrissi) and Lars Uhlin, an educational developer, using a 'patchwork strategy' utilising social media to loosely 'stitch' learning spaces together without advanced technical expertise (Wenger, White, and Smith 2009). Weller's categorisation of 'big OERs' (those that are institutional initiatives such as MOOCs) and 'little OERs' (practitioner 'grass roots'

*Corresponding author. Email: c.nerantzi@mmu.ac.uk

Responsible Editor: Meg O’Reilly, Southern Cross University, Australia.

Research in Learning Technology 2015. (C) 2015 C. Nerantzi. Research in Learning Technology is the journal of the Association for Learning Technology (ALT), a UK-based professional and scholarly society and membership organisation. ALT is registered charity number 1063519 . http://www.alt.ac.uk/. This is an Open Access article distributed under the terms of the Creative Commons Attribution 4.0 International License (http://creativecommons.org/licenses/by/4.0/), allowing third parties to copy and redistribute the material in any medium or format and to remix, transform, and build upon the material for any purpose, even commercially, provided the original work is properly cited and states its license. 


\section{Nerantzi}

initiatives) seeks to illustrate the difference between OER in terms of flexibility. For example, a small team can create a 'little OER', like FDOL, and it can be tailored rapidly to provide a dynamic and flexible learning experience - in this case one that flexibly provides an evolving continuing professional development (CPD) opportunity for practitioners who support learning in HE.

FDOL was offered as a collaborative cross-institutional educational opportunity to HE professionals who teach or support learning in two institutions (one in the United Kingdom and one in Sweden - each of which assessed the unit with different tasks), but it was also available to open learners. The course was thus concurrently open and/or formally credit bearing depending upon each participant's choice. Table 1 outlines the three developmental iterations of FDOL.

This research explores the views of participants about the problem-based learning (PBL) model (FISh: focus, investigate and share) used within the FDOL132 course to foster collaborative learning in small groups.

\section{Open education and online courses}

UNESCO (2015) describes open education resources (ranging from textbooks to curricula, syllabi, lecture notes, assignments, tests, projects, audio, video and animation) as in the public domain, which are freely available to be shared, used and adapted. Open education, therefore, has the potential to reach those who need access to learning most and contributes towards the democratisation of education (Lane 2009). This, coupled with technological advancements in the past few decades, has enabled distributed communities to connect, support each other and openly share resources (Dwyer and Suthers 2005; Stahl, Koschmann, and Suthers 2006; Wenger, White, and Smith 2009). Developments such as these have opened up new possibilities and a vision grew to spread open educational practices (Conole 2013), including some within academic CPD. For example, Bennett's (2014) research around digital practitioners shows that they are proactively engaging in professional development while others find it challenging to make the transition, and Nerantzi and Beckingham's (2014) work illustrates how open development opportunities can lead to engagement by less digitally confident practitioners who are keen to enhance their practice.

Table 1. FDOL iterations FDOL 131, FDOL132, FDOL141 and available quantitative data.

\begin{tabular}{|c|c|c|c|}
\hline & FDOL131 & FDOL132 & FDOL141 \\
\hline Duration & $\begin{array}{l}12 \text { weeks } \\
\text { (Spring 2013) }\end{array}$ & $\begin{array}{l}12 \text { weeks } \\
\text { (Winter 2013) }\end{array}$ & $\begin{array}{l}6 \text { weeks } \\
\text { (spring 2014) }\end{array}$ \\
\hline $\begin{array}{l}\text { Learners registered total (includes } \\
\text { both open and formally registered } \\
\text { students) (UK/Sweden/Others) }\end{array}$ & $80(42 / 21 / 17)$ & $107(65 / 20 / 22)$ & $86(38 / 27 / 21)$ \\
\hline $\begin{array}{l}\text { Number of FISh groups (each group } \\
3 \text {-10 learners) }\end{array}$ & $\begin{array}{l}\text { Initially } 8 \\
\text { (reduced to } 4 \text { ) }\end{array}$ & $\begin{array}{l}\text { Initially } 4 \\
\text { (reduced to 3) }\end{array}$ & $\begin{array}{l}\text { Initially } 6 \\
\text { (reduced to 4) }\end{array}$ \\
\hline $\begin{array}{l}\text { Learners in groups } / \% \text { (group } \\
\text { membership was optional) }\end{array}$ & $\begin{array}{l}64 \text { out of } \\
80 / 80 \%\end{array}$ & $\begin{array}{l}31 \text { out of } \\
107 / 29 \%\end{array}$ & $\begin{array}{l}27 \text { out of } \\
86 / 32 \%\end{array}$ \\
\hline FISh Facilitators & 4 & 4 & 14 (in pairs/threes) \\
\hline $\begin{array}{l}\text { Number of learners who completed } \\
\text { the course whilst working in groups }\end{array}$ & $\begin{array}{l}16 \text { out of } 64 \\
(25 \%)\end{array}$ & $\begin{array}{l}13 \text { out of } 31 \\
(43 \%)\end{array}$ & $\begin{array}{l}17 \text { out of } 27 \\
(63 \%)\end{array}$ \\
\hline
\end{tabular}


As teaching in HE has been encouraged to be professionalised (Browne Report 2010; Dearing Report 1997; DfES 2003), institutions have offered a variety of initial and continuous development opportunities for academics and other professionals who teach or support learning, and more recently, more outward facing, open and collaborative models of CPD offers have started appearing (Nerantzi 2011a, 2012; Cochrane et al. 2014; Smyth et al. 2013). These create rich and authentic development opportunities and connect professionals in wider communities (Cochrane et al. 2014). UK examples include an open course from Oxford Brooks University, an OER module from the University of Wolverhampton, as well as open cross-institutional development events organised by Manchester Metropolitan University and Sheffield Hallam University such as Bring Your Own Devices for Learning (BYOD4L) and Flexible, Open and Social (FOS) Learning.

\section{Course pedagogy FISh: small groups and PBL}

In the 1960s, cooperative learning in small groups began to interest educators and researchers (Johnson and Johnson 1999; Johnson, Johnson, and Smith 2007). Research revealed that cooperative learning helps to bring individuals together and creates more inclusive learning communities (Coleman 1961). In the late 1960s, PBL started to be used, initially in medical education (Barrows and Tamblyn 1980), as a pedagogy designed for enquiry-based collaborative learning; initially face-to-face, and more recently in blended and online settings (Chernobilsky, Nagarajan, and HmeloSilver 2005; Donnelly 2009). In a highly formalised PBL application, group members take on rotating roles, and a specific model is used to structure the process of enquiry. In PBL, learners define their own learning outcomes linked to learning scenarios or triggers (Hmelo-Silver et al. 2009; Savin-Baden 2003) and are supported by facilitators (Savin-Baden 2003).

Computer-Supported Collaborative Learning (CSCL) developed in the 1990s (Stahl, Koschmann, and Suthers 2006) is largely based on Scardamalia's and Bereiter's (1994) Computer-Supported Intentional Learning Environment (CSILE). CSCL helped educators realise the role that technologies and the new possibilities offered could play in the facilitation of online learning particularly using collaboration in small groups and communities (Dwyer and Suthers 2005; Stahl, Koschmann, and Suthers 2006).

FDOL emphasises online collaborative learning using PBL particularly foregrounding the small groups' social construction of knowledge. A three-step PBL model called FISh (Nerantzi and Uhlin 2012) that provides a scaffold for group activities was utilised (see appendix 2). FISh played a key role in engaging participants in groups in PBL using specific learning scenarios to build understanding and knowledge collaboratively and with the support of facilitators.

Research has shown that PBL can be effective for in-depth authentic and contexualised learning (Savin-Baden 1996). However, there is limited research into its use as a pedagogy in open educational practices (Nerantzi 2012).

\section{Background to FDOL}

FDOL emerged from an online open PBL study in which one of the authors (Chrissi) tested the viability of an idea bringing together distributed collaborative learning using PBL involving colleagues studying on institutional teaching qualification 


\section{Nerantzi}

programmes (Nerantzi 2011a, 2012). The take up of the course, for its three offers, is outlined in Table 1 below.

Facilitators from both institutions and elsewhere supported learners through a variety of methods including asynchronous and synchronous participation in course activities via social media platforms. Facilitators were present in the open FDOL community in Google + and fostered course related conversations. Some also acted as FISh group facilitators within each group space to support functionality and PBL activities.

\section{Research aims, data collection and analysis}

This research aims to explore participants' views in relation to the FISh model's effectiveness in promoting learning within FDOL. An invitation to participate in this study was sent to all 107 FDOL132 participants at the beginning of the course. In total, 18 expressed interest and provided consent.

An initial survey was sent to these 18 participants shortly after the start of the course. The purpose of this survey was to gain an insight into background; motivation to participate in the course; prior experience of online, open and collaborative learning; what helps them learn, as well as basic demographic information. The survey was completed by 16 participants (14\% response rate).

Shortly after the end of the course, a final online survey was sent to all 18 study participants which collected information regarding participants' engagement with the course, their views about the support provided, what they felt helped them learn and to what extent they had met their learning goals. Eleven of the participants completed the survey, and seven of them agreed to be interviewed (details in Table 2). Individual semi-structured interviews were conducted surfacing themes in respect of the research aim as lived by the participants.

Epistemologically, this exploratory research is situated in constructivist/interpretive paradigm concerned with describing phenomena as they are experienced (Bassey 1990). The qualitative analysis utilised Thomas (2006) general inductive approach to systematically review the qualitative data.

University ethical approval was obtained prior to commencing the study, and all course participants were contacted and invited to take part. Each interview, via Skype, lasted between 45 and 60 minutes, was digitally recorded and subsequently transcribed. Transcriptions were sent back to the participants for checking. Once agreed, the transcriptions were entered into NVivo to facilitate analysis. Through an iterative analysis process the transcripts were coded, and the themes were identified.

\section{Themes and discussion}

Four themes emerged from the analysis:

(1) PBL as an enabler for community building

(2) PBL as a design for collaborative learning

(3) Collaborative learning as a process

(4) Time constraints impact engagement 
Research in Learning Technology

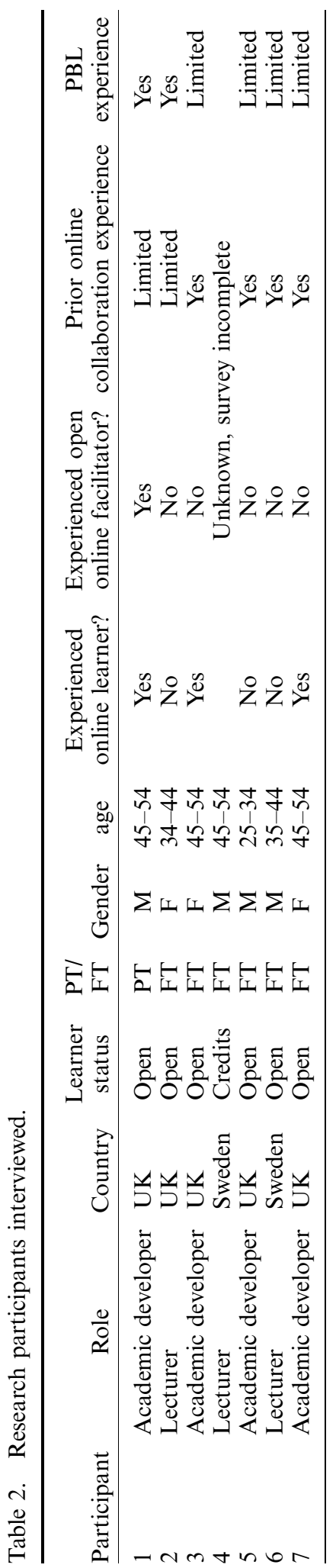




\section{Nerantzi}

\section{$P B L$ as an enabler for community building}

PBL (FISh) as a pedagogy using groups was useful as a strategy for socialisation and created a sense of belonging and community. This was welcomed and valued especially as the participants were in cross-disciplinary and cross-cultural groups.

I wasn't prepared to do it on my own because I didn't have a reason to do it. I like the collaboration, even though it was frustrating, organizing the groups and expecting everybody to contribute. When we got together, the four of us, I liked the fact that I was learning from the others. And to be honest, this is the most useful course I ever have done because I'm learning from others. (Participant 7)

It was a good way [...] to meet new people. I widened my network in Sweden and abroad. (Participant 6)

In Salmon's (2013) five-stage model of learning and teaching online, socialisation features at stage two after access and motivation. Molka-Danielsen and Brask (2014) also note that creating opportunities for socialisation, from the outset, is important for online learning. Participants reported that connecting via a webcam using Google Hangout was seen as beneficial as it enabled opening up to others in the group and connecting with them.

It's about being able to read the other person's body language. [. . .] That's what I assume it is [...]. I just feel that it was, that gave it the personal feel [...]. I felt like I knew everybody because I knew what they looked like [...]. I think that made a difference. Then they weren't just [...] an icon on a computer screen, I'd recognised them as a human being [laughs] if that makes sense. (Participant 2)

PBL for community building in the context of an open course was seen as valuable as it enabled participants to get to know each other, personalise their learning experience and feel part of a community. This had, according to participants, a positive effect on working in groups increasing commitment, motivation and engagement.

Because a couple of members of the group were very motivated. ... actually [laughs] if you don't do work you feel ashamed, you know, you let your group down. (Participant 7) I was quite lucky to work in a group that everybody wanted to say something and do something. (Participant 7)

The opportunity to learn at a more personal level with others in the PBL groups, while still being able to connect with other open participants 'in the big lecture sense' (Participant 6), was also seen as beneficial and created additional opportunities to connect and become part of a wider community.

[...] it's great talking about communities, but [...] as with all communities, there are sub-, subfeatures, so to speak, subsets of that. And sometimes they can be very useful to help learners feel kind of safer [...]. (Participant 1)

\section{PBL as a design for collaborative learning}

The majority of participants in this study noted that PBL was an enabler for collaborative learning in groups and stressed that the support and guidance provided by the facilitators was important (see also Nerantzi 2011b; Nerantzi, Middleton, and Beckingham 2014). 
[...] it [PBL] worked for me because of that particular group, and the facilitator and everything worked. (Participant 7)

Some participants stated that they enjoyed the experience of how PBL works. The simplified PBL model FISh (Figure 1) was seen as useful.

I really enjoyed [...] the visual dimension to it. [...] the use of image. I love the illustration (FISh), I think that is great. [...] I like visual metaphor. [...] it did get me thinking about things in a slightly different way. (Participant 5)

Overall, the PBL design was seen as an effective way to enable collaborative learning. However, the exclusive use of FISh for group work was questioned by one participant.

I'm not convinced that using one particular, educational approach [FISh] is necessarily always the best thing. Particularly if you're trying to bring people together .... OK, structuring, is important, and putting people in groups but ... to kind of feed them through, a certain educational approach, I'm not [...] always convinced by that. (Participant 1)

The notion of choice in relation to how learning happens is also discussed by Wells, Jones, and Jones (2014) as a positive strategy for teaching, whereas Dillenbourg (1999) talks about collaborative learning as a 'social contract' that leads to agreement via negotiation instead of the application of an imposed pedagogical approach.

Due to varying levels of commitment and engagement, there were also challenges using and rotating the traditional PBL roles such as chair, time keeper and scribe.

Well based on the experience with FDOL, it was useful to have a sense that there should be a chair and scribe and other roles, within the decision-making process, I think in other ways it's, it's much easier online to just volunteer yourself or be just that little but more autocratic, in the way in which a decision is made. [...] felt as though that was happening in our PBL group, that when we were co-authoring a Google doc whilst having a Hangout, that we were just volunteering ourselves, and simultaneously putting our name against a part of the FISh template. (Participant 5)

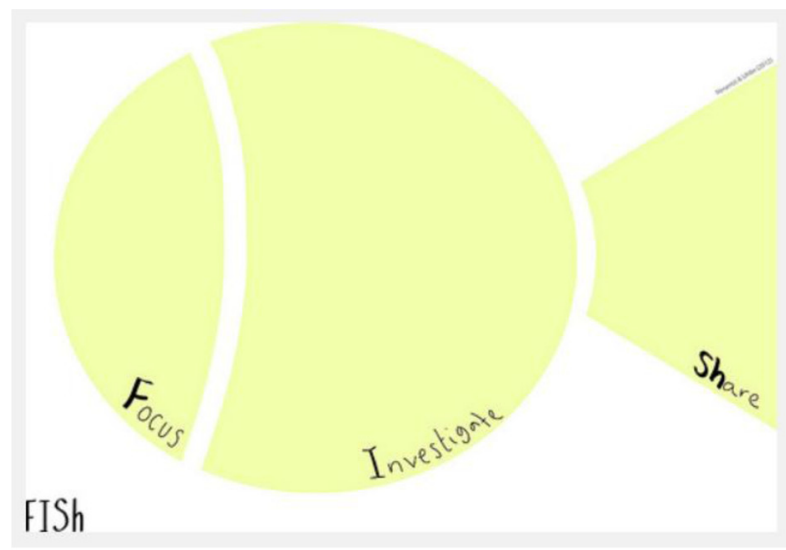

Figure 1. FISh model. 


\section{Nerantzi}

All participants agreed that smaller groups worked effectively.

I just wonder whether from my experience of when only two or three of us met for a Hangout, you know [...], everybody has to interact then, to a certain extent, whereas if there's six of you, it's much easier for two people to stay quiet. (Participant 2)

Dillenbourg's (1999) research confirms that smaller group sizes of four or five seem to work most effectively. While his work in this area relates to face-to-face settings, evidence shows that smaller group sizes also work better in online settings (Donnelly 2009; Novak 1989). In a study by Oliver and Omari (1999) examining the use of online PBL within an undergraduate programme, they reported that students worked in groups of $4-5$.

We [group sizes] were more like 3, 2, 5 people and of course it is smaller group, it is easier to feel safe, to feel connected with the people there .... (Participant 6)

It was suggested by some that greater flexibility for collaborative learning could be added through a buddy system within the groups, and the use of alternative group working strategies could be considered as well.

I think that's where, the smaller the group is, or even if it's the subsections of what you're doing. [...] It means that you're much more in the same way that you notice it, it is exactly the same when you do it in face-to-face lecturing - you'll have people that don't want to stand up in front of forty, but are quite happy to lead a seminar in front of ten, or something like that. (Participant 2)

\section{Collaborative learning as a process}

Mixing individuals, who were working towards credits with others who were not, did not appear to influence participants' capacity to contribute to the tasks. However, in order to make the collaborative learning more effective, participants suggested that there should be greater transparency about the credit status of each group member.

I didn't know Participant 4 was doing that [working for credits] ... it sounds harsh to say it made no difference .... You know, we all tried to contribute as much as we could. (Participant 3)

Participants also commented on the varied level of engagement, which had an impact on collaboration. Group membership was voluntary, and participants engaged to different degrees with their allocated groups.

The main challenge for us [...], was, inconsistent levels of engagement. [...] I don't think, it is a reflection of commitment, it's just chance. So, one member happened to be very busy one week another member happened to be on holiday, for a couple of weeks, some of us couldn't attend certain sessions. (Participant 5)

When we first were put into groups, it was actually getting the group dynamic right. [...] Um, understanding how, how we might work together [...] Because we seemed to have people who seemed to be, on the face of it, very keen, but then they soon disappeared .... Which was really destabilising, trying to get that sense of group cohesion. (Participant 3) 
The interviews revealed that participants felt that FISh activities were disproportionately focused on producing a group output or product rather than on the collaborative process itself, and for some, this was problematic.

I'm not sure within that amount of time, whether or not we just spent the entire time just trying to produce something, rather than actually using it as a, a thorough way of grappling with the theme of that week. (Participant 5)

I think maybe the product was not really the most important thing of the PBL group. Maybe the way [we worked] was actually more important than the product, the artefact of the group. (Participant 4)

One participant who worked towards assessment proposed:

Then this [assess the quality of the product] might be a motivation for students to increase the quality of the product, you could also strengthen the role of peer reviewing aspects. [...] there was not so much focus on peer reviewing and critical discussion of the products and if you could adjust the priorities [then] maybe the quality of the products would be better. (Participant 4)

Not all learners were working towards assessment. This suggests that participants would have found it more beneficial if the groups focused more on collaboration as a process. This is an interesting finding especially as collaboration is often seen as a co-development of shared output based on a group goal (Dillenbourg 1999; Laurillard 2012; Roschelle and Teasley 1995). Dillenbourg (1999), however, departs from this position and argues that in collaborative learning group members might or might not have a shared goal. He suggests that collaborative learning is a shared process and uses the term 'learning from collaboration' (Dillenbourg 1999, p. 5) in contrast to collaboration for the production of a product where groups co-create a shared output.

Integrating opportunities for reflection and experimentation as well as learning for personal outcomes and outputs, linked to practice, were seen as desirable.

[...] my motivation was there because I was interested in how it relates to me with my practice so I guess that's where I wanted the outcome to lead to. (Participant 5)

It [the course] was something that has made changes to my approach to teaching and made changes to what I do in practice. It's something that's made me want to learn more. (Participant 2)

Similar motivations were found in a digital practitioner project in which participating teachers felt that it was important to be able to apply their learning to their own practice and enhance the student experience (Bennett 2014).

The authenticity of the scenarios used also helped participants to relate these to their own practice and contextualise their learning (Savin-Baden 1996), while one participant found the freedom to create their own scenario valuable.

I did feel engaged because ... the topic of the activity or the scenario that we have used was [from] our experience. So if it was another scenario then it would not have worked for me. But because it was experiential learning, it just worked perfectly .... I liked the scenario because it was authentic. [...] I could relate and it reflected what I was doing in my professional life as well. (Participant 7) 


\section{Nerantzi}

Synchronous collaborative learning supported by Google hangouts seemed to work well.

A little bit of excitement ... was a combined use of Google Hangouts with Google Drive. Several of us were present in the conversation live and together in the document. [...] it is a very efficient and productive way of getting stuff done ... it's a very rich and inclusive way of making everybody feel as though they're contributing [...] at the same time. So, that was really powerful. (Participant 5)

\section{Time constraints impact engagement}

Participants in this study were all in employment, and juggling professional and private lives with the course demands - a theme which emerged in the interviews. Participants' availability was a real challenge which impacted on course engagement. Bennett's (2014) research around the digital practitioner revealed similar time constraint issues for academics engaging in CPD related to technology-enhanced learning. Nerantzi, Middleton, and Beckingham (2014) in a study around open facilitators found similar issues.

I think it is difficult because everybody has a job, we have a private life and the, limited time for this course was a big challenge because we were doing this at night, at the weekend and, at the extra hours where we had a long day of work behind us. So this, was difficult. (Participant 4)

I [...] have recently, just changed jobs, which, you know, fundamentally shifted my professional working and access to just [IT] kit, basically, all sort of things, you know, and just time. (Participant 5)

The participants' experiences reveal that they were committed to the course and their fellow group members. However, a participant highlighted that study time was 'eating' into personal time.

I was suppose to do this mostly in my work time. But I didn't have time to do this [. . .] so I did it mostly in the evenings, at home instead. ... which meant of course that I had to sacrifice things that I would do in my spare time. (Participant 4)

Participants came up with alternative delivery options for this course. Some suggested a shorter duration, whereas others suggested study breaks or offering the course in the summer. It is important to identify ways to offer CPD that is manageable and fits around academic life (Nerantzi 2011a). Busy professionals often struggle to find the time to fully participate, not due to lack of interest or commitment, but due to real time constraints.

\section{Conclusion and lessons learnt}

The themes emerging from this study are of value in the context of the professional development of teachers in $\mathrm{HE}$ and the findings of this study are encouraging about the opportunities presented by FISh used with small facilitated PBL groups in the open course FDOL. It is clear that the OER provided CPD learning opportunities for the participants, and evidence from this study illustrates that:

- FISh was an enabler for community building and collaborative learning despite time pressures. 
- The authenticity of the scenarios and the opportunity to situate these within participant's own practice played a key role in motivation and engagement.

- Collaboration as a process was seen as more valuable than creating a joint output/product within the FISh groups.

- Synchronous online learning was seen as beneficial especially when participants could see each other and work together at the same time.

- Time pressures and conflicting priorities did hinder some in participating in synchronous online activities which had a negative impact on group cohesion.

The findings present new opportunities for exploration and research in open educational practice around collaborative learning generally and PBL specifically. Creating a body of evidence in this area to help course designers make informed decisions and enhance the learner experience in such settings is important.

The idea of offering a more flexible and inclusive approach to group work with a more varied pedagogical design for collaborative learning tailored to a specific group, their commitment, availability and strengths, is important as choice and negotiation creates a sense of shared ownership which can be empowering. Conceiving of collaboration as a shared learning process, as envisaged by the FISh model, rather than as a shared output could enable smoother learning relationships to develop that in turn will foster more personalised and contextualised learning and we suggest that this especially the case if learners are from different disciplines or professional areas. Dillenbourg (1999, p. 5) outlines the term 'learning from collaboration' to define the shared process in which mechanisms of learning (such as knowledge elicitation, and internalisation) are triggered. However, we feel that 'collaboration as learning' might be a better term as it gives more emphasis to the process than the product of the collaboration. As Dillenbourg (1999) notes, the processes triggered within collaborative learning cannot be guaranteed but they only can occur during collaboration. Within this FDOL CPD situation (and perhaps all group work), this need to be more clearly articulated to the participants.

FISh as a PBL model (broadly) works in enabling collaboration in an online learning environment. However, as our conclusion, we offer three keys factors to consider. First, that time needs to be invested into the development of working learning relationships. Second, and closely related, that the PBL model (in this case FISh) needs to be collectively understood as an important process (rather than for participants to be focused on the problem's solution). Third, and finally, that the problem must be authentic and resonate with the participants (in this case it needed to be recognised as a useful CPD activity).

\section{Acknowledgements}

We thank all research participants for sharing their valuable insights and the FDOL codeveloper Lars Uhlin, as well as our colleague Dr Charles Neame who kindly commented on the draft.

\section{References}

Barrows, H. S. \& Tamblyn, R. M. (1980) Problem-Based Learning. An Approach to Medical Education, Springer, New York.

Bassey, M. (1990) 'On the nature of research in education (Part 1 \& Part 2)', Research Intelligence, vol. 36, pp. 35-44. 


\section{Nerantzi}

Bennett, L. (2014) 'Learning from the early adopters: developing the digital practitioner', Research in Learning Technology, vol. 22, no. 2014, [online] Available at: http://www. researchinlearningtechnology.net/index.php/rlt/article/view/21453/html

Browne Report. (2010) Securing a Sustainable Future for Higher Education, Department for Employment and Learning, Available at: http://www.delni.gov.uk/index/publications/ pubs-higher-education/browne-report-student-fees.htm

Chernobilsky, E., Nagarajan, A. \& Hmelo-Silver, C. E. (2005) 'Problem-based learning online: multiple perspectives on collaborative knowledge construction', CSCL'05 of the 2005 Conference on Computer Support for Collaborative Learning: The Next 10 Years', pp. 53-62, [online] Available at: http://www.edu-projects.eu/euclides/elibrary/Chernobilsky.pdf

Cochrane, T., Antonczak, L., Keegan, H. \& Narayan, V. (2014) 'Riding the wave of BYOD: developing a framework for creative pedagogies', Research in Learning Technology, vol. 22, pp. $1-14$.

Conole, G. (2013) MOOCs as Disruptive Technologies: Strategies for Enhancing the Learner Experience and Quality of MOOCs [Preprint], e-LiS, [online] Available at: http://eprints. rclis.org/19388/

Coleman, J. S. (1961) The Adolescent Society, The Free Press of Glencoe, New York.

Dearing Report. (1997) Higher Education in the Learning Society, Department for Education and Employment, [online] Available at: http://www.leeds.ac.uk/educol/ncihe/

DfES. (2003) The Future of Higher Education. HMSO, Norwich.

Dillenbourg, P. (1999) 'What do you mean by collaborative learning?', in CollaborativeLearning: Cognitive and Computational Approaches, ed P. Dillenbourg, Elsevier, Oxford, pp. $1-19$.

Donnelly, R. (2009) 'The nexus of problem-based learning and learning technology: does it enable transformative practice?', European Journal of Open, Distance and E-Learning, 2009/II, [online] Available at: http://www.eurodl.org/?p=current\&article $=371$

Dwyer, N. \& Suthers, D. (2005) 'A study of the foundations of artefact-mediated collaboration', Paper Presented at the International Conference of Computer-Supported Learning (CSCL 2005), Taipei, Taiwan, pp. 135-144.

Hmelo-Silver, C. E., et al., (2009) 'Targeting transfer in a STELLAR PBL course for pre-service teachers', The Interdisciplinary Journal of Problem-Based Learning, vol. 3, no. 2, pp. 24-42.

Johnson, D. W. \& Johnson, R. (1999) Learning Together and Alone: Cooperative, Competitive, and Individualistic Learning, 5th edn, Allyn \& Bacon, Boston, MA.

Johnson, D. W., Johnson, R. \& Smith, K. (2007) 'The state of cooperative learning in postsecondary and professional settings', Educational Psychology Review, vol. 19, pp. 15-29.

Lane, A. (2009) 'The impact of openness on bridging educational digital divides', The International Review of Research in Open and Distance Learning, vol. 10, no. 5, [online] Available at: http://www.irrodl.org/index.php/irrodl/article/view/637

Laurillard, D. (2012) Teaching as a Design Science. Building Pedagogical Patters for Learning and Technology, Routledge, Oxon.

Molka-Danielsen, J. \& Brask, O. D. (2014) 'Designing virtual collaboration environment for distance learners: exploring socialization as a basis for collaboration', in Nordic Contributions in IS Research. Lecture Notes in Business Information Processing, vol. 186, eds T. H. Commisso, J. Norbjerg \& J. Pries-Heje, Springer, Cham, pp. 74-89.

Nerantzi, C. (2011a) 'Anyone There?' Online Problem-Based Learning within Academic Development, Unpublished MSc dissertation, Edinburgh Napier University.

Nerantzi, C. (2011b) 'Not too much facilitation going on' - issues in facilitating online problem-based learning in academic development', Celebrating the Past and Embracing the Future: Evolution and Innovation in Problem-Based Learning, Conference Proceedings, 30 \& 31 March 2011, Problem-Based Learning Special Interest Group of the Higher Education Academy Health Sciences and Practice Subject Centre, UCLAN, Preston, pp. 111-124.

Nerantzi, C. (2012) 'A case of problem-based learning for cross-institutional collaboration', Special European Conference in E-Learning, Brighton 11, Special Issue, The Electronic Journal of e-Learning, vol. 10, no. 3, pp. 306-314.

Nerantzi, C. \& Beckingham, S. (2014) 'BYOD4L: no doors, no locks!' Conference presentation at Designing Learning Landscapes: Mobile, Open, Inclusive. Learning and Teaching Conference, Goldsmiths University, 30 May 2014, [online] Available at: http://www.slideshare.net/ chrissi/cn-sb-goldsmithsnodoorsnolocksv2 
Nerantzi, C., Middleton, A. \& Beckingham, S. (2014) 'Facilitators as co-learners in a collaborative open course for teachers and students in higher education', Learning in Cyberphysical Worlds, eLearning Paper, no. 39, pp. 1-10, [online] Available at: http://www. openeducationeuropa.eu/en/article/Learning-in-cyber-physical-worlds_From-field_39_2

Nerantzi, C. \& Uhlin, L. (2012) FDOL Design, [online] Available at: https://fdol.wordpress. com/fdol131/design/

Novak, J. (1989) 'Helping student learn how to learn: a view from a teacher-researcher', Third Congress of Research and Teaching in Science and Mathematics, Santiago de Compostela, Spain, September. Reviewed in PS News 69.

Oliver, R. \& Omari, A. (1999) 'Using online technologies to support problem-based learning: Learners' responses and perceptions', Australian Journal of Educational Technology, vol. 15, no. 1 , pp. $58-79$.

Roschelle, J. \& Teasley, S. (1995) 'The construction of shared knowledge in collaborative problem solving' in Computer-Supported Collaborative Learning, ed C. O' Malley, Springer Verlag, Berlin, Germany, pp. 69-197.

Salmon, G. (2013) E-tivities: The Key to Active Online Learning, 2nd edn, Routledge, Oxon.

Savin-Baden, M. (1996) Problem-Based Learning: A Catalyst for Enabling and Disabling Disjunction Prompting Transitions in Learner Stances? Unpublished PhD thesis, University of London, Institute of Education.

Savin-Baden, M. (2003) Facilitating Problem-Based Learning, Illuminating Perspective, Maidenhead, SRHE and Open University Press.

Scardamalia, M. \& Bereiter, C. (1994) 'Computer support for knowledge-building communities', The Journal of Learning Sciences, vol. 3, no. 3, pp. 256-283.

Smyth, K., et al., (2013) 'Cross-institutional development of an online open course for educators: confronting current challenges and imagining future possibilities', in Electric Dreams. Proceedings Ascilite 2013, eds H. Carter, M. Gosper \& J. Hedberg, Macquarie University, Sydney, pp. 826-829.

Stahl, G., Koschmann, T. \& Suthers (2006) 'Computer-supported collaborative learning: an historical perspective', in Cambridge Handbook of the Learning Sciences, ed R. K. Sawyer, Cambridge University Press, Cambridge, pp. 409-426.

Thomas, D. (2006) 'A general inductive approach for analyzing qualitative evaluation data', American Journal of Evaluation, vol. 27, no. 2, pp. 237-246.

UNESCO. (2015) What Are Open Educational Resources (OERs)? [online] Available at: http://www.unesco.org/new/en/communication-and-information/access-to-knowledge/openeducational-resources/what-are-open-educational-resources-oers/

Weller, M. (2011) The Digital Scholar. How Technology Is Transforming Scholarly Practice, Bloomsbury, London.

Weller, M. (2014) The Battle for Open Webinar, The Ed Techie, 21 March 2014, [online] Available at: http://nogoodreason.typepad.co.UK/

Wells, H., Jones, A. \& Jones, S. C. (2014) 'Teaching reluctant students: using the principles and techniques of motivational interviewing to foster better student-teacher interactions', Innovations in Education and Teaching International, vol. 51, no. 2, pp. 175-184.

Wenger, E., White, E. \& Smith, J. D. (2009) Digital Habitats. Stewarding Technology for Communities, CPSquare, Portland. 


\title{
C. Nerantzi
}

Appendix 1. Module aims and leaning outcomes.

\begin{abstract}
Aims
To provide opportunities for learners' engagement in inclusive and flexible pedagogies and collaborative open practices that support learning in the digital age aligned with the UK PSF and/or SEDA Values where relevant.

To provide opportunities to develop learners' understanding of the benefits and challenges involved in designing flexible pedagogical interventions supported by technology in face-toface, blended and fully online mode.

To provide learners opportunities for reflection on their practice based on the experience as learner in open educational settings.

\section{Intended Learning Outcomes}

On successful completion of this course, learners will be able to:

Reflect on how inclusive and flexible pedagogies can be used within their teaching context aligned with the UK PSF and/or SEDA Values where relevant.

Discuss benefits and challenges which influence the use of flexible pedagogies supported by technologies in higher education.

Reflect on their experience as learners in open educational settings.
\end{abstract}

Appendix 2: FISh stages

Step 1: Focus

- What do I/we see?

- How do $\mathrm{I} / \mathrm{we}$ understand what we see?

- What do I/we need to find out more about?

- Specify learning issues/intended learning outcomes!

Step 2: Investigate

- How and where am I/are we going to find answers?

- What will I do/who will do what and by when?

- What main findings and solutions do I/we propose?

Step 3: Share

- How am I/are we going to present my/our findings?

- What do $\mathrm{I} /$ we want to share with the community?

- How can $\mathrm{I} /$ we provide feedback to others?

- What reflections do I have about my learning (and working with others)? 